\title{
EDITORIAL
}

\section{CIENCIA Y ENFERMERÍA: HACIENDO FRENTE A NUEVOS DESAFÍOS}

T as publicaciones periódicas, como Ciencia y Enfermería, son un instrumento básico para el desarrollo de cualquier comunidad científica. Actúan como un registro oficial y público de la ciencia de enfermería, constituyen el principal vehículo para difundir la información científica y son fuentes de consumo y apropiación del conocimiento generado. Es sabida la complejidad que significa mantener la regularidad de publicaciones científicas de calidad, así como, acceder a indexaciones como el International Scientific Index (ISI) de la empresa Thomson Scientific, más aún en nuestra área y especialmente en el contexto latinoamericano, donde con honrosas excepciones, han accedido a ésta, pero, nuestro quehacer editorial debe ir direccionado hacia allá. Como gestores de información, es nuestra misión el compromiso con esta "empresa editorial" que representa la edición de una revista científica, que se genera tanto en formato papel como en versión electrónica. Con este objetivo y, teniendo en mente que nuestra revista se perfeccione en presencia y visibilidad en la comunidad profesional y académica, manteniendo su calidad, es que nos hemos propuesto los siguientes cambios en su formato:

- aumento del número de trabajos por edición, desde el presente número;

- modificación de las normas para presentar la referencias bibliográficas, a contar del próximo número, según el estilo Vancouver, originadas del International Committee of Medical Journal Editors.

Reconociendo el esfuerzo editorial que esto significa y el necesario apoyo de nuestros colaboradores, es que esperamos ir respondiendo así, tanto al espíritu de las primeras editoras de la revista, como a la comunidad de enfermería que la procura y reconoce el valor de este vehículo de difusión de la disciplina.

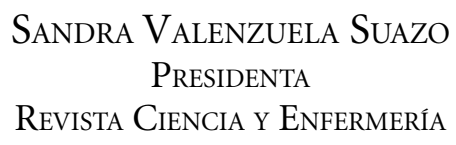

